\title{
GAIA Level of Diagnostic Certainty
}

National Cancer Institute

\section{Source}

National Cancer Institute. GAIA Level of Diagnostic Certainty. NCI Thesaurus. Code C126828.

A classification of maternal and fetal outcomes developed by the Global Alignment of Immunization safety Assessment in pregnancy, based on the extent to which the diagnosis has been confirmed. 